BULLETIN Bulletin hispanique

HISPANIQUE Université Michel de Montaigne Bordeaux

121-1 | 2019

La épica en el mundo hispánico (Siglo de Oro)

\title{
Roger Boase, Secrets of Pinar's Game. Court Ladies and Courtly Verse in Fifteenth-Century Spain
}

Leiden: Brill, 2017

Pedro Ruiz Pérez

\section{(2) OpenEdition}

\section{Journals}

Edición electrónica

URL: https://journals.openedition.org/bulletinhispanique/8197

DOI: 10.4000/bulletinhispanique.8197

ISSN: 1775-3821

\section{Editor}

Presses universitaires de Bordeaux

Edición impresa

Fecha de publicación: 24 junio 2019

Paginación: 371-374

ISBN: $979-10-300-0363-5$

ISSN: 0007-4640

\section{Referencia electrónica}

Pedro Ruiz Pérez, «Roger Boase, Secrets of Pinar's Game. Court Ladies and Courtly Verse in Fifteenth-

Century Spain», Bulletin hispanique [En línea], 121-1 | 2019, Publicado el 24 junio 2019, consultado el 02 enero 2023. URL: http://journals.openedition.org/bulletinhispanique/8197 ; DOI: https://doi.org/ 10.4000/bulletinhispanique.8197

Este documento fue generado automáticamente el 2 enero 2023.

All rights reserved 


\title{
Roger Boase, Secrets of Pinar's Game. Court Ladies and Courtly Verse in Fifteenth-Century Spain
}

Leiden: Brill, 2017

\author{
Pedro Ruiz Pérez
}

\section{REFERENCIA}

Roger Boase, Secrets of Pinar's Game. Court Ladies and Courtly Verse in FifteenthCentury Spain. - Leiden: Brill, 2017. 916 p. (2 vols.).

1 A pesar de contar con una bibliografía crítica no escasa ni desorientada, la lírica cancioneril peninsular en el siglo XV sigue siendo en cierta medida un territorio por roturar desde el punto de vista filológico y exegético. A disposición del lector interesado se encuentra ya un buen número de ediciones fiables, en particular en lo que toca a los poetas mayores y a los grandes cancioneros colectivos, así como algunas aproximaciones de valor crítico; el monumental catálogo-índice de Brian Dutton permite una completa cartografía del territorio, y equipos, proyectos y asociaciones completan el panorama actual de un asedio en el que la orientación interpretativa apunta una interesante renovación de perspectivas. En este proceso, no obstante, hay espacio sobrado para sumar aportaciones de valor, $y$, sin duda, una de ellas, y relevante, es la que nos proporciona Roger Boase, con su edición y estudio de un texto que se encontraba aún a la espera de una aproximación como la que aquí se nos propone y que se convierte en un hito de sustancial trascendencia, tanto para la valoración intrínseca de la obra de Gerónimo Pinar como para una decodificación más cabal de la poesía cancioneril y su funcionamiento pragmático en el entorno cortesano de las décadas finales del siglo XV, justo cuando se están configurando, en el plano sociocultural, los rasgos característicos del terreno que acogerá la semilla de la renovación renacentista. 
2 El Juego trobado (1496-1498), pese a su valor y trascendencia, no contaba hasta el momento con una edición exenta ni con un acercamiento crítico de suficiente solvencia, quizá por lo problemático de su carácter y, sobre todo, de su interpretación. Se trata, en efecto, de un conjunto compuesto por 46 pequeñas piezas en verso que fungen con valor de naipes, muy posiblemente destinados al entretenimiento de las damas y, quizá en menor medida, de sus galanes y compañeros de salón. Su carácter lúdico no excluía su aportación al reforzamiento de unos lazos de sociabilidad muy específicos del entorno cortesano y caballeresco, en los que la existencia de los mismos era tan importante como el modo en que articulaban una concreta axiología y su correspondiente jerarquización. Conformando en su agrupación una especie de baraja, cada carta estaba compuesta por una copla real, con un encabezamiento a modo de identificación de la destinataria, porque, en efecto, todas ellas, salvo una, están enderezadas a una dama de la corte, entre la aristocracia de la sangre y el servicio en el entorno de la reina Isabel; la única excepción o, más bien, singularidad en el conjunto es el caso del príncipe Juan, cerca de su temprana y frustrante muerte, integrado poéticamente en el conjunto por su cercanía a la reina, su juventud y su papel en esta vertiente de la corte, si no es que el desfile de damas y los valores que se les atribuyen no sirven de speculum para la formación en aquellos principios áulicos que no son estrictamente políticos, aunque con un indudable peso en lo trabado de la construcción. Así lo pone de relieve la luz que la investigación minuciosa de Boase arroja sobre estos versos un tanto herméticos; pero habremos de volver a ello más adelante.

Desconocemos las reglas de lo que con toda probabilidad constituiría un entretenimiento con dosis en distinto grado de azar y capacidad de respuesta e interacción entre los participantes. Tampoco en las huellas textuales que conservamos se halla una identificación inequívoca de las figuras en danza. El halo de misterio, por no hablar de hermetismo en su significado, se cierne así sobre unas coplas que, al sacarse de su contexto, apenas tienen valor poético, además de mostrar una cierta monotonía en la reiteración sistemática de los cuatro referentes que integran la apelación dirigida a la destinataria. Los dos primeros, el árbol y el ave, pertenecen a los codificados repertorios simbólicos que nutrían las divisas caballerescas, a partir de enciclopedias y bestiarios de distinta índole, aunque al personalizarlos adquieren significados y alusiones muy precisas que era necesario descodificar para devolverlos a la pragmática en la que su valor poético se instala. Más interesante, si cabe, son los dos componentes finales de la caracterización oblicua de la dama en las coplas, ya que en sus últimos versos se alude a otra composición poética, antes de cerrarse con la cita de un refrán, en este caso generalmente transcrito en su integridad. Es obvia la trascendencia de esta práctica, siempre que se completa la labor de identificación, ya que, además de confirmar la relación del cancionero cortesano con la paremiología (y basta recordar a Santillana), supone una referencia documental de primer orden al repertorio de composiciones líricas no sólo realmente existentes, sino circulando en el entorno cortesano con tal intensidad (de ejercicio y de memoria), que podían tener un reconocimiento eficaz sólo con la mención del primer verso.

4 Se define así un corpus de trabajo tan atractivo para su estudio como disuasorio por el nivel de dificultad. Por suerte para la filología y el conocimiento histórico, Roger Boase se ha dejado seducir por su canto de sirenas, pero con la suficiente habilidad como para sortear sirtes y bajíos en la travesía crítica y vencer a base de erudición, pero también de buen criterio, los obstáculos que impedían el acceso al sentido de los versos. Se 
trataba, en la mayor parte de los casos, de dificultades propias de la Esfinge, hechas de omisiones y silencios, que no eran tales en el contexto de creación y que hoy, sin la ayuda del filólogo, se nos convierten en verdaderas lápidas exegéticas, propias de un mausoleo, de brillante apariencia y materia inerte en su interior. Pocos géneros o subgéneros en la literatura occidental nacieron y se desarrollaron tan estrechamente vinculados a un contexto como la lírica cancioneril cortesana, y pocos códigos aunaron con tanta intensidad en una retórica sintética la ideología del cortejo galante, la del orden feudal y la de un universo de analogías. El resultado es un lenguaje cifrado, un hortus conclusus en el marco de un salón, sin llave para los profanos. En esa categoría bien podríamos entrar los lectores del siglo XXI, alejados no sólo de un universo de referencia, sino en especial medida, de un determinado modo de leer o, por mejor decir, de participar en una práctica del verso con mucho de performatividad.

5 El trabajo del profesor Boase viene a responder en modo prácticamente completo a los efectos de esta dificultad. Su metodología parte de la recomposición en dimensiones enciclopédicas del universo de referencia y del sistema de relaciones que trababa su arquitectura. Con ella recompone un edificio en el que, con la lectura de sus páginas, se reabre el espacio de la corte y el escenario de los juegos sociales en los que se urdían unas relaciones a la vez personales y estamentales, afectivas y de intereses materiales. En un ejercicio de refinada filología y de rigurosa historiografía el estudioso hace en su edición de estos centenares de versos un minucioso despliegue, es decir, explicación de su red de referencias y alusiones más o menos oblicuas, enlazando saberes y noticias de personas y de textos, de hechos y de creencias. El resultado de una empresa así, comparable a la que Herrera trenzó en torno a los poemas de Garcilaso, va más allá del esclarecimiento de los versos de Pinar y las intenciones de su composición. Como en las Anotaciones se sintetiza el saber poético del momento y se sienta las bases para su renovación, los secrets of Pinar's Game dejan de serlo, para mostrarnos el horizonte lírico y mental de un cronotopo específico, pero muy representativo, al tiempo que con su revelación propician otra mirada sobre la obra y sobre el género en que se inscribe. A partir del Juego trobado, y sin dejar de atender a su correcta edición y esclarecimiento, lo que Boase nos ofrece es algo parecido a una piedra de Rosetta, como la que permitió a Champollion el acceso a la escritura jeroglíflica del antiguo Egipto.

6 Con algo de aquel sistema de pictogramas y con mucho de su carácter hierático, con puntos de esotérico, el código cortés y su expresión en la lírica cancioneril, más allá de sus manifestaciones más convencionales y epidérmicas, se conformó a modo de signo de distinción del selecto grupo de los happy few, adaptándose a sus usos y valores, refractario al acceso de los no inicados, los "secretos del juego" como son caracterizados en el título de nuestra obra, unos secretos ahora desvelados junto con los procedimientos que permitían generar y comprender los discursos, con tanto de ejercicio lírico como de práctica social. Buena muestra de esta realidad la encontramos en los materiales del segundo tomo de la obra, acompañando a lo que ya sería una cumplida edición de la obra de Pinar. Al localizar, recoger y comentar los poemas citados en el Juego trobado (junto con su traducción), el editor y estudioso no se limita a añadir un apéndice erudito para comodidad de la lectura, a la vez que una ilustrativa muestra antológica de la poesía en circulación viva en los años finales de la centuria. El alcance de este monumental empeño filológico es mucho mayor, al revelar la estrecha relación existente, más que en el corpus, en el código de la lírica cortesana, tan intertextual como ideológicamente connotada. Revela también el planteamiento conceptual y el rigor metodológico de Boase, cuando la erudición profunda se pone al 
servicio de una consistente visión crítica sobre el cosmos genérico del verso cortesano, una visión que ahora podemos compartir sobre la solidez de este trabajo, que nos ilustra tanto sobre uno de los capítulos líricos más complejos de nuestra historia literaria como sobre la pertinencia y la vigencia de un método que se sustenta sobre el respeto al texto, parte de él y puede alzarse a pináculos de alcance panorámico e interpretativo. Sin duda, estamos ante un valioso texto recuperado, pero no menos ante una lectura crítica de indudable trascendencia.

\section{AUTORES}

PEDRO RUIZ PÉREZ

Universidad de Córdoba 